\title{
Efeito do tamoxifeno no perfil das proteínas plasmáticas em condição de diabetes mellitus tipo $1^{1}$
}

\author{
Teresa Cristina P. Silva², Saul B. Mota ${ }^{3}$, Maria Margareth C. Almeida ${ }^{2}$, Elaine Cristina S. Ferreira², \\ Marcela A. G. Ururahy ${ }^{4}$, João Felipe Bezerra ${ }^{4}$, Ney M. L. Pereira' ${ }^{5}$, Ana M. O. Ramos ${ }^{6}$, \\ Maria das Graças Almeida ${ }^{7}$, Adriana A. Rezende ${ }^{8}$
}

\begin{abstract}
Silva TCP, Mota SB, Almeida MMC, Ferreira ECS, Ururahy MAG, Bezerra JF, Pereira NML, Ramos AMO, Almeida MG, RezendeAA. Efeito do tamoxifeno no perfil das proteínas plasmáticas em condição de diabetes mellitus tipo 1. Acta Cir Bras [serial on line] Available from: URL: htt://www.scielo.br/acb.

RESUMO - Objetivo: Considerando-se que importantes avanços científicos têm sido obtidos através de estudos com Diabetes mellitus experimental, e que a ação do tamoxifeno em humanos permanece obscura, o presente trabalho objetiva acompanhar as modificações promovidas pelo diabetes e tamoxifeno no perfil eletroforético das proteínas plasmáticas. Métodos: Foram utilizados 27 ratos fêmeas Wistar (180-220g peso corporal), divididos randomicamente em 5 grupos: $\mathrm{C} 1$ ( $\mathrm{n}=3$, receberam veículo), C2 ( $\mathrm{n}=3$, sem tratamento), $\mathrm{T}$ ( $\mathrm{n}=5$, tratados com tamoxifeno, $0,3 \mathrm{mg} / \mathrm{kg} / \mathrm{dia}$ ), $\mathrm{D}$ ( $\mathrm{n}=8$, diabéticos experimentais por estreptozotocina, $45 \mathrm{mg} / \mathrm{Kg}$ ) e DT $(\mathrm{n}=8$, diabéticos tratados com tamoxifeno). A eletroforese foi realizada em acetato de celulose, $\mathrm{pH}$ 8,6-8,8, cuba TECNOW, e as fitas foram coradas em Ponceau S. As proteínas totais foram determinadas pelo método do Biureto (Kit Labtest). Os proteinogramas foram obtidos em densitômetro BioSystems BTS-235. Resultados: Albumina diminuiu progressivamente nos grupos T, D e DT; a fração a aumentou nos grupos T e DT; a fração a aumentou nos grupos T e D, havendo efeito aditivo no grupo DT; a fração b aumentou nos grupos Te D; a fração g aumentou nos grupos T, D e DT. Conclusão: Os resultados indicam uma resposta de fase aguda, com efeito aditivo do tamoxifeno e diabetes, sugerindo uma provável lesão hepática.
\end{abstract}

DESCRITORES: Tamoxifeno. Proteínas plasmáticas. Diabetes mellitus. Eletroforese de proteínas.

\section{Introdução}

O tamoxifeno (TAM) é o agente antiestrogênico não esteroidal comumente utilizado no tratamento do câncer de mama e mais recentemente seu uso tem sido aprovado na quimioprevenção em mulheres com elevado risco de desenvolvimento de câncer de mama. Atua bloqueando a ação do estrogênio, que por sua vez, estimula a divisão celular na mama ${ }^{1,2,3}$. O TAM pode produzir efeito estrogênico total ou parcial, bem como efeito antagonista, dependendo do tecido alvo e da espécie estudada. Existem dois receptores estrogênicos (RE), a e b, onde as diferenças entre estes subtipos de receptores em relação à afinidade de ligação e distribuição nos tecidos poderiam contribuir para explicar a ação seletiva dos agonistas ou antagonistas do RE em diferentes órgãos e sistemas. Este fármaco apresenta ação agonista em determinados tecidos, como o endometrial (aumentando o risco de câncer de endométrio), o ósseo (prevenindo a osteoporose pré e pós-menopausa) e o hepático (metabolismo lipoprotéico), e apresenta ação antagonista na mama ${ }_{1,4,5}$. O tratamento com tamoxifeno está associado com aumento do risco de câncer endometrial, trombose, embolia pulmonar e esteatose hepática ${ }^{2,5,6}$.

As proteínas são polímeros de aminoácidos unidos por ligações covalentes denominadas de ligações peptídicas. Os diferentes grupamentos $\mathrm{R}$ encontrados nos aminoácidos influenciam na estrutura, funcionalidade e nas propriedades das proteínas individuais, que podem ser usadas para a sua separação, identificação e dosagem ${ }^{7}$. Dentre as técnicas de separação de proteínas encontra-se a eletroforese, que se refere à migração de solutos ou partículas carregadas sob a influência de um campo elétrico. A velocidade de migração eletroforética depende de muitos fatores, que incluem carga elétrica global da molécula, tamanho e forma da molécula, intensidade do campo elétrico, propriedades do meio de sustentação e temperatura de operação. Em um proteinograma obtido do soro normal, costumam ser observadas duas frações, sendo uma de albumina e outra composta pelas globulinas que são divididas em a ${ }_{1} \mathrm{a}_{2}, \mathrm{~b}$ e g globulinas ${ }^{8}$.

O processo infamatório agudo decorrente de infecções, danos teciduais ou provenientes de outros estímulos, induz

\footnotetext{
1 Trabalho realizado pelo Programa de Pós-Graduação em Ciências Farmacêuticas da Universidade Federal do Rio Grande do Norte, Natal - RN, Brasil.

2 Aluna de Mestrado do Programa de Pós-Graduação em Ciências Farmacêuticas, Centro de Ciências da Saúde, UFRN.

3 Farmacêutico Bioquímico graduado pela UFRN.

4 Acadêmico de Farmácia da UFRN, bolsista do programa de Iniciação Cientifica PIBIC/ CNPq.

5 Mestre em Bioquímica - Departamento de Bioquímica da UFRN, Farmacêutico da Oncoclínica São Marcos, Natal - RN.

6 Professora, Doutora, do Departamento de Patologia da UFRN.

7 Professora, Doutora, Coordenadora do Programa de Pós-Graduação em Ciências Farmacêuticas da UFRN

8 Professora, Doutora, Vice-coordenadora do Programa de Pós-Graduação em Ciências Farmacêuticas da UFRN
} 
uma série complexa de reações que tem como finalidade inibir a continuidade do dano tecidual, isolando e destruindo o organismo agressor e ativando o processo de reparação necessário para o retorno do organismo às funções normais. A inflamação aguda é geralmente acompanhada por uma resposta sistêmica, conhecida como resposta de fase aguda, que é caracterizada por uma rápida alteração nos níveis das várias proteínas plasmáticas. Há liberação de amplo espectro de mediadores por parte dos macrófagos teciduais e monócitos sanguíneos, dos quais as citocinas, principalmente o fator de necrose tumoral (TNF) e as interleucinas IL-1 e IL-6, são as principais mediadoras da síntese das proteínas de fase aguda séricas. Durante a resposta inflamatória, a ligação destas citocinas aos seus respectivos receptores nos hepatócitos induz a produção do fator de transcrição específico do fígado NF-IL6, que promove a transcrição dos genes que codificam diversas proteínas de fase aguda. Coincidentemente, os níveis do fator de transcrição $\mathrm{C} / \mathrm{EBP}$, que é expresso constitutivamente nos hepatócitos e que promove a transcrição da albumina e transferrina, diminuem e os níveis de albumina e transferrina, conseqüentemente diminuem. Desta maneira o aumento da síntese de proteínas reagentes de fase aguda positivas é acompanhado de uma diminuição na síntese de pré-albumina, albumina e transferrina (proteínas reagentes negativos da fase aguda), de modo que só ocorre um leve aumento do total de proteínas do plasma. O aumento da concentração das proteínas de fase aguda séricas, designadas como reagentes de fase aguda (RFA), ocorre de forma proporcional à intensidade da agressão e da destruição tecidual. Supõe-se que todas tomem parte no complexo processo defensivo da inflamação, para tanto, apresentam ação antiproteásica e antioxidante, podendo agir, como ativadores do sistema complemento. Os níveis plasmáticos das proteínas individuais da fase aguda sobem com velocidades diferentes. Primeiro, a proteína C-reativa (PCR) e a antiquimotripsina; depois, dentro das primeiras 12 horas, a a glicoproteína ácida (AAG); em seguida, a a -antitripsina (AAT), haptoglobina, C4 e fibrinogênio; e, finallmente, C3 e ceruloplasmina. As proteínas reagentes de fase aguda são consideradas indicadores mais fiéis da resposta sistêmica frente aos processos inflamatórios e infecciosos, quando comparadas a outras variáveis, tais como febre, aumento da taxa de hemossedimentação e/ou presença de leucocitose associada a neutrofilia. Embora a resposta de fase aguda não seja específica, pode ser usada na prática clínica como parte do diagnóstico, tanto na avaliação da intensidade da atividade inflamatória como na discriminação de doenças inflamatórias das não-inflamatórias. Além disso, são úteis na monitorização da resolução tecidual de traumas ou inflamação e também na avaliação da resposta orgânica ao tratamento. Dessa forma, a detecção de um processo inflamatório agudo necessita de medida sensível e rápida de proteínas de fase agu$\mathrm{da}^{9,10,11,12,13,14,15}$.

Na maior parte das condições patológicas que envolvem as proteínas plasmáticas, as alterações abrangem não apenas uma determinada proteína, mas um grupo razoavelmente am- plo dos componentes protéicos, dando lugar a quadros mais característicos dos processos fisiopatológicos. A interpretação racional, com base no conhecimento do significado fisiológico e fisiopatológico de cada componente, e das associações entre as alterações dos diversos componentes, pode trazer indicações úteis ao diagnóstico ${ }^{8}$.

O Diabetes mellitus tipo 1 é uma doença inflamatória autoimune associada com alterações na permeabilidade vascular, levando a muitas complicações incluindo nefropatia, retinopatia, hipertensão, e neuropatia. A disfunção endotelial tem sido consistentemente demonstrada em modelos animais de diabetes, bem como em pacientes com diabetes tipo 1 e tipo 2, sendo sugerido que o processo inflamatório está envolvido na patogênese da disfunção endotelial e da aterosclerose. Estes dados são confirmados pela observação de níveis elevados de proteína $C$ reativa, um marcador de inflamação sistêmica, em pacientes com intolerância a glicose. Além disso, correlações entre proteína $\mathrm{C}$ reativa e marcadores da disfunção endotelial tem sido relatadas tanto em pacientes diabéticos tipo 1 como em pacientes diabéticos tipo 2. Dentre os fatores que podem contribuir para o estado inflamatório vascular no diabetes estão o estresse oxidativo, a hiperglicemia, os produtos de glicação avançados (AGEs) e a oxidação do LDL (lipoproteína de baixa densidade). Tanto a inflamação intra-arterial como o estímulo extravascular pode induzir ativação da resposta de fase aguda, levando a um ${ }_{16}$ aumento de parâmetros inflamatórios como a proteína $\mathrm{C}$ reativa

GOMES et al, estudaram um grupo de pacientes com diabetes mellitus tipo 1 sem complicações clínicas macro e microvasculares para determinar se os níveis de proteínas de fase aguda (alfa 1 glicoproteína ácida, proteína $\mathrm{C}$ reativa e fibrinogênio) estavam alterados e se esses níveis de proteínas de fase aguda estavam relacionados com o controle glicêmico. De acordo com os resultados obtidos, as proteínas de fase aguda, um conhecido marcador de inflamação, apresentaram-se aumentadas em pacientes com diabetes mellitus tipo 1 quando comparados aos controles, independentemente do controle glicêmico ${ }^{17}$.

A variedade de proteínas séricas encontradas em ratos é diferente daquelas encontradas em humanos. Algumas proteínas séricas estão presentes em concentrações muito mais baixa em ratos do que em humanos, como por exemplo, a haptoglobina em condições basais. Outras proteínas estão presentes em concentrações bem mais elevadas em ratos, como é o caso da proteína C reativa. Algumas proteínas são espécie especifica para ratos, como é o caso da expressão da a1 macroglobulina em condições basais e da expressão da proteína serina inibidora 3 durante um processo inflamatório ${ }^{18}$.

Recentes investigações sobre proteínas séricas têm demonstrado que as diferenças qualitativas e quantitativas entre as espécies de ratos (Sprague-Dawley, Lewis e Wistar Kyoto) são mínimas, pelo menos em condições basais. Do mesmo 
modo outros estudos mostraram que a idade pouco influenciou no padrão das proteínas séricas dos ratos estudados, porém GIANAZZA et al ${ }^{18}$ encontrou diversas diferenças no perfil protéico entre machos e fêmeas: a hemopexina e a proteína $\mathrm{C}$ reativa são aproximadamente $50 \%$ e $25 \%$, respectivamente mais altas em fêmeas, enquanto que a a1antitripsina é aproximadamente $30 \%$ mais alta em machos ${ }^{18}$.

Considerando que importantes avanços científicos têm sido obtidos através de estudos realizados em animais com Diabetes mellitus experimental e que a ação do tamoxifeno em humanos ainda permanece obscura, o presente trabalho tem por objetivo acompanhar as modificações promovidas pelo DM, bem como pelo TAM, no perfil eletroforético das proteínas plasmáticas.

\section{Métodos}

\section{Animais}

Foram utilizados 27 ratos fêmeas da linhagem Wistar, de peso entre $180 \mathrm{~g}$ - $220 \mathrm{~g}$, fornecidos pelo Biotério do Centro de Ciências da Saúde da Universidade Federal do Rio Grande do Norte, mantidos em gaiolas com no máximo três animais, com água e ração comercial purina ad libitum, e com ciclo claroescuro $12 / 12 \mathrm{~h}$

Os animais foram divididos em cinco grupos: Grupo $(\mathrm{C} 1)$ : $\mathrm{n}=3$ animais recebendo apenas veículo (sorbitol + tween $20+$ carboximetilcelulose - CMC); Grupo (C2): n=3 animais sem qualquer tipo de tratamento; Grupo (T): $n=5$ animais com tratamento exclusivo com tamoxifeno; Grupo (D) $n=8$ animais diabéticos experimentais por estreptozotocina; e Grupo (DT): $\mathrm{n}=8$ animais diabéticos experimentais em tratamento com tamoxifeno.

Durante o período de 30 dias, foi feita pesagem semanal dos animais e observação do quadro de poliúria, polidipsia e polifagia para os animais diabéticos experimentais. Foi realizada a avaliação das fases do ciclo estral dos animais de acordo com DUARTE et al ${ }^{19}$. Após o período de 30 dias, os animais foram sacrificados por deslocamento cervical.

Todos os procedimentos em relação aos animais foram executados de acordo com o Guia padrão para Cuidados e Uso de animais de laboratórios ${ }^{20}$.

\section{Indução do diabetes mellitus}

Após jejum alimentar não hídrico, ad libitum, por cerca de 12 horas, ratos Wistar fêmeas de aproximadamente 180-220g receberam, por via intraperitoneal, estreptozotocina (Sigma) dissolvida em tampão citrato de sódio 0,01M, pH 4,5, na proporção de $45 \mathrm{mg} / \mathrm{kg}$ de peso corporal ${ }^{19}$.

\section{Tratamento com tamoxifeno}

Os animais foram tratados diariamente com tamoxifeno, por via oral, em uma proporção de $0,3 \mathrm{mg} / \mathrm{kg} / \mathrm{dia}$, por um período de 30 dias. $\mathrm{O}$ tamoxifeno foi preparado em solução aquosa de sorbitol $10 \%$ contendo carboximetilcelulose (CMC) $0,5 \%$ e 10 gotas de Tween 20 .

\section{Preparo das amostras de sangue}

As amostras de sangue destinadas à avaliação foram obtidas dos animais submetidos a jejum alimentar não hídrico, $a d$ libitum, por cerca de 8-10 horas, sendo estas analisadas no período de 30 dias. Os animais foram sacrificados por deslocamento cervical e submetidos à coleta de cerca de $6 \mathrm{~mL}$ de sangue.

O sangue coletado, em um tubo sem anticoagulante, foi centrifugado utilizando uma centrífuga de bancada não refrigerada Sigma 2-3 à $1.500 \mathrm{~min}^{-1}$, durante 10 minutos. O soro obtido foi utilizado para a dosagem de glicose, proteínas totais e posterior eletroforese de proteínas.

\section{Determinação da concentração de glicose}

A determinação da concentração de glicose foi realizada utilizando-se o método da enzima glicose oxidase peroxidase (kit LABTEST), em um espectrofotômetro RA 50 (Bayer Diagnósticos, Irlanda, 1998).

\section{Determinação da concentração de proteínas totais}

A determinação da concentração das proteínas totais foi realizada utilizando o método do Biureto, onde as ligações peptídicas das proteínas (-HN-CO-) reagem com íons cúpricos em meio alcalino (Reagente do Biureto) formando um complexo de coloração violeta, cuja absorbância medida em 545 nm (espectrofotômetro RA 50 - Bayer Diagnósticos, Irlanda, 1998) é diretamente proporcional à concentração de proteínas na amostra.

\section{Eletroforese em acetato de celulose}

A eletroforese das proteínas plasmáticas foi realizada utilizando-se fitas de acetato de celulose Midifilm (5,7 x $14 \mathrm{~cm}-$ Biomidi), e como amostra o soro dos animais experimentais. Foi utilizada uma cuba eletroforética TECNOW e a migração das proteínas séricas foi realizada em tampão Tris-Veronal (Biomidi) pH 8,6 - 8,8. As fitas de acetato de celulose foram previamente incubadas no mesmo tampão por dez minutos para em seguida serem posicionadas na cuba e receberem as amostras. A aplicação ocorreu no pólo negativo da cuba utilizando cerca de 3 a $5 \mathrm{ml}$ de soro. Após migração de 50 minutos as fitas foram coradas em Ponceau S 5g/L, por aproximadamente 8 minutos, e descoradas em solução aquosa de ácido acético a 5\%. A seguir, foram fixadas em metanol PA por 1 minuto e transparentizadas em solução de $85 \%$ metanol, $14 \%$ ácido acético PA, $1 \%$ glicerina por 2 minutos. Finalmente foram secas em estufa à $60^{\circ} \mathrm{C}$, durante 5 minutos, e a leitura do resultado e quantificação das frações protéicas foi realizada por densitometria, usando o densitômetro BioSystems BTS 235. O aparelho mede a superfície de cada pico e deduz a percentagem. Utilizando a concentração das proteínas totais, previamente determinada, o aparelho deduz a quantidade de cada fração em g/dL. 


\section{Análise estatística}

Os dados obtidos foram submetidos à análise de variância (ANOVA) para saber se existia diferença significativa entre os grupos estudados para cada fração do proteinograma, e em seguida o teste de Tukey foi aplicado para detectar quais as médias apresentavam diferença significativa. $\mathrm{O}$ nível de rejeição da hipótese de nulidade foi fixado em 5\% ( $\mathrm{p} £ 0,05)$. Foi utilizado o programa STATISTICA for Windows versão 5.1 e o programa Excel 2000 MicrosoftÒ para a montagem dos bancos de dados e gráficos.

\section{Resultados}

\section{Avaliação do ciclo estral}

As fases do ciclo estral dos animais controles apresentaramse regulares durante todo o período de estudo, entretanto para os grupos T, D e DT observou-se que as fases do ciclo estral apresentaram-se irregulares ou mesmo estacionadas durante horas ou mesmo dias na mesma fase. Considerando que a irregularidade do ciclo estral não interferiu no perfil eletroforético das proteínas plasmáticas, todos os animais foram utilizados (resultados não mostrados).

\section{Caracterização do estado diabético}

A caracterização do estado diabético experimental dos animais utilizados foi realizada através do acompanhamento da glicemia (Figura 1) e da evolução do peso corporal (Figura 2) de cada animal, por um período de 30 dias. Os animais diabéticos apresentaram-se hiperglicêmicos 24 horas após a administração de estreptozotocina, com valores médios de glicemia sempre superiores a $250 \mathrm{mg} / \mathrm{dL}$.

Em relação ao ganho de peso corporal os animais controles atingiram um peso médio de $210 \mathrm{~g}$ enquanto que os diabéticos experimentais o peso médio final foi de 180 - 190g.

\section{Avaliação dos proteinogramas}

A avaliação geral dos proteinogramas revelou que todos os animais apresentaram perfis eletroforéticos dentro do padrão geralmente obtido para humanos, onde as proteínas séricas são separadas em 2 frações distintas, sendo uma de albumina e outra composta pelas globulinas, entre elas a , a , b e g globulinas. A Tabela 1 mostra os respectivos valores da média e desvio padrão das frações protéicas obtidas para cada grupo estudado, no período de 30 dias, e a Figura 3 mostra a representação gráfica do comportamento das frações protéicas para cada grupo estudado, a partir dos quais será possível avaliar as possíveis alterações observadas em função do tratamento realizado.
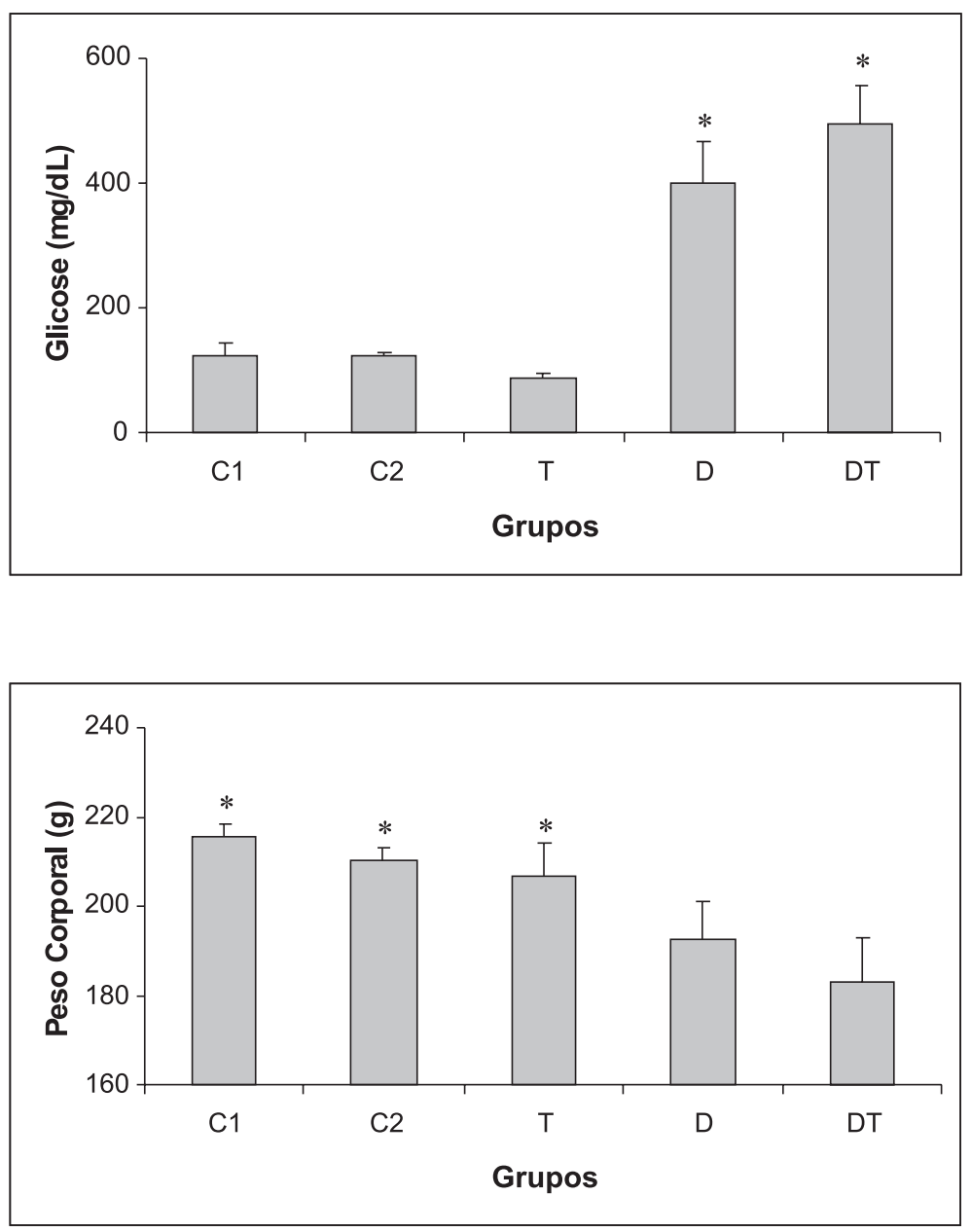

FIGURA 1 - Glicemia dos animais controle com veículo (C1), controle sem veículo (C2), tratados com tamoxifeno (T), diabéticos (D) e diabéticos tratados com tamoxifeno (DT), durante o período de 30 dias. Os resultados são expressos como média \pm desvio padrão. * (p < 0,05) vs C1, C2, T

FIGURA 2 - Peso corporal dos animais controle com veículo (C1), controle sem veículo (C2), tratados com tamoxifeno (T), diabéticos (D) e diabéticos tratados com tamoxifeno (DT), durante o período de 30 dias. Os resultados são expressos como média \pm desvio padrão. * $(\mathrm{p}<0,05)$ vs D, DT 


\begin{tabular}{|c|c|c|c|c|c|c|c|c|c|c|c|c|}
\hline \multirow{2}{*}{ Frações } & \multicolumn{2}{|c|}{$\begin{array}{l}\text { Valores } \\
\text { Referência }\end{array}$} & \multicolumn{2}{|c|}{$\mathrm{C} 1$} & \multicolumn{2}{|c|}{$\mathrm{C} 2$} & \multicolumn{2}{|c|}{$\mathbf{T}$} & \multicolumn{2}{|c|}{ D } & \multicolumn{2}{|c|}{ DT } \\
\hline & $\%$ & $\mathrm{~g} / \mathrm{dL}$ & $\%$ & $\mathrm{~g} / \mathrm{dL}$ & $\%$ & $\mathrm{~g} / \mathrm{dL}$ & $\%$ & $\mathrm{~g} / \mathrm{dL}$ & $\%$ & $\mathbf{g} / \mathbf{d L}$ & $\%$ & $\mathbf{g} / \mathbf{d L}$ \\
\hline $\begin{array}{l}\text { Albumin } \\
\text { a }\end{array}$ & $\begin{array}{l}53,0- \\
68,0\end{array}$ & $3,5-4,8$ & $\begin{array}{l}65,3 \\
? 1,5\end{array}$ & $5,02 ? 0,1$ & $\begin{array}{l}62,3 \\
? 5,1\end{array}$ & $\begin{array}{l}4,98 \\
? 0,4\end{array}$ & $\begin{array}{l}53,8 \\
? 3,2^{*}\end{array}$ & $\begin{array}{l}3,99 \\
? 0,2^{*}\end{array}$ & $\begin{array}{l}49,0 \\
? 4,4^{*}\end{array}$ & $\begin{array}{l}3,72 \\
? 1,0^{*}\end{array}$ & $\begin{array}{l}44,4 \\
? 3,4^{*}\end{array}$ & $3,27 ? 0,4^{*}$ \\
\hline Alfa 1 & $1,6-4,5$ & $\begin{array}{l}0,12- \\
0,32\end{array}$ & $4,4 ? 0,5$ & $0,28 ? 0,1$ & $3,0 ? 0,2$ & $\begin{array}{l}0,34 \\
? 0,2\end{array}$ & $5,5 ? 0,5$ & $\begin{array}{l}0,36 \\
? 0,1\end{array}$ & $3,5 ? 0,7$ & $\begin{array}{l}0,26 \\
? 0,1\end{array}$ & $5,4 ? 0,3$ & $0,38 ? 0,1$ \\
\hline Alfa 2 & $5,7-11,5$ & $\begin{array}{c}0,41- \\
0,83\end{array}$ & $3,0 ? 0,4$ & $\begin{array}{c}0,23 \\
? 0,03\end{array}$ & $3,9 ? 1,2$ & $\begin{array}{l}0,31 \\
? 0,1\end{array}$ & $5,6 ? 1,0$ & $\begin{array}{l}0,38 \\
? 0,1\end{array}$ & $4,8 ? 0,5$ & $\begin{array}{l}0,47 \\
? 0,2\end{array}$ & $\begin{array}{r}11,6 \\
? 1,7^{?}\end{array}$ & $\begin{array}{r}0,64 \\
? 0,3^{?}\end{array}$ \\
\hline Beta & $8,0-14,2$ & $0,5-1,3$ & $\begin{array}{l}12,4 \\
? 0,7\end{array}$ & $0,96 ? 0,5$ & $\begin{array}{c}14,6 ? \\
0,1\end{array}$ & $\begin{array}{l}1,02 \\
? 0,3\end{array}$ & $\begin{array}{l}15,8 \\
? 0,4\end{array}$ & $\begin{array}{l}1,18 \\
? 0,2\end{array}$ & $\begin{array}{l}21,4 \\
? 1,5^{+}\end{array}$ & $\begin{array}{c}1,39 \\
? 0,3^{+}\end{array}$ & $\begin{array}{l}22,0 \\
? 2,8^{+}\end{array}$ & $\begin{array}{c}1,23 \\
? 0,4^{+}\end{array}$ \\
\hline Gama & $\begin{array}{l}10,5- \\
19,5\end{array}$ & $0,75-1,4$ & $\begin{array}{l}17,4 \\
? 0,4\end{array}$ & $1,21 ? 0,2$ & $\begin{array}{c}17,7 ? \\
0,3\end{array}$ & $\begin{array}{l}1,34 \\
? 0,2\end{array}$ & $\begin{array}{l}19,0 \\
? 1,2\end{array}$ & $\begin{array}{l}1,44 \\
? 0,3\end{array}$ & $\begin{array}{l}22,4 \\
? 1,7^{+}\end{array}$ & $\begin{array}{c}1,35 \\
? 0,3^{+}\end{array}$ & $\begin{array}{l}21,5 \\
? 1,0^{*}\end{array}$ & $1,51 ? 0,4^{*}$ \\
\hline
\end{tabular}

TABELA 1 - Valores relativos e absolutos das frações protéicas obtidas a partir do proteinograma dos animais controle com veículo (C1), controle sem veículo (C2), tratados com tamoxifeno ( $\mathrm{T}$ ), diabéticos (D) e diabéticos tratados com tamoxifeno (DT)

Os valores são expressos como média \pm Desvio Padrão.

$*(\mathrm{p}<0,05)$ vs $\mathrm{C} 1, \mathrm{C} 2$.

$\bullet(\mathrm{p}<0,05)$ vs C1, C2, T, D.

$+(\mathrm{p}<0,05)$ vs $\mathrm{C} 1, \mathrm{C} 2, \mathrm{~T}$.

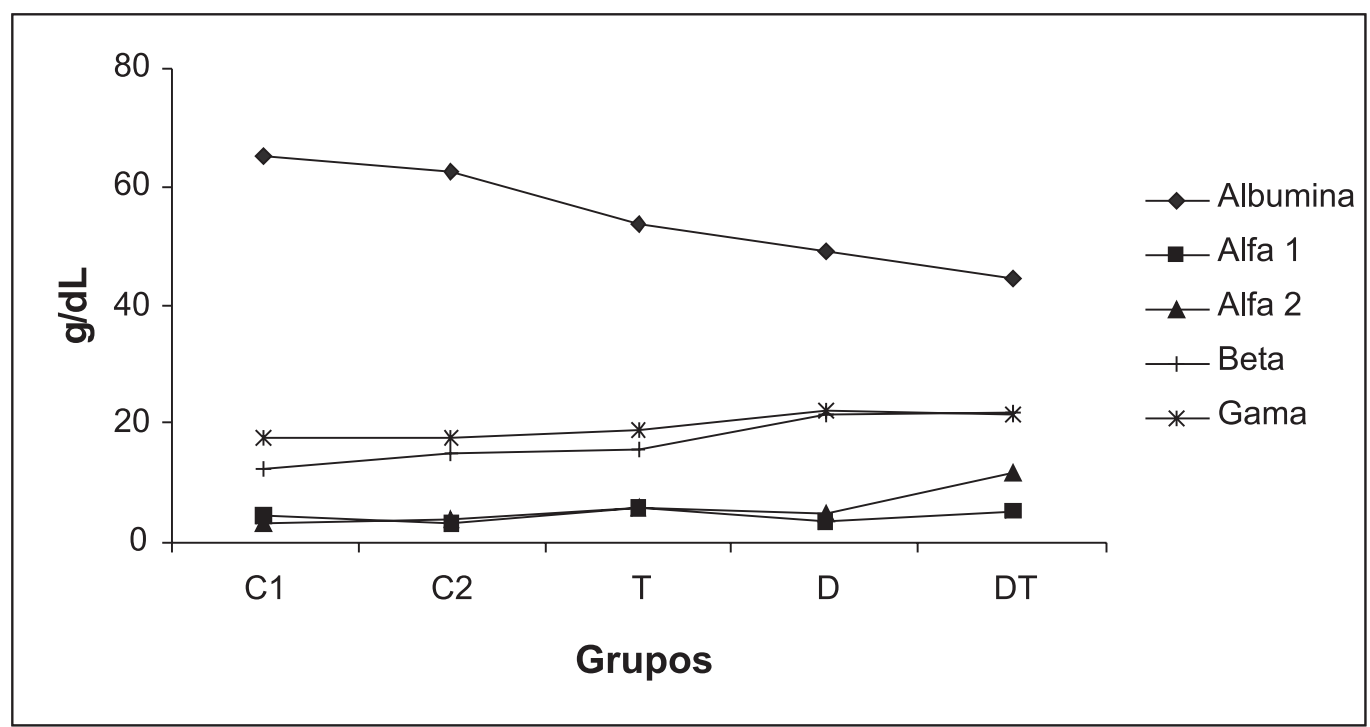

FIGURA 3 - Evolução das frações protéicas dos animais controle com veículo $(\mathrm{C} 1)$, controle sem veículo (C2), tratados com tamoxifeno (T), diabéticos (D) e diabéticos tratados com tamoxifeno (DT), durante o período de 30 dias

\section{Discussão}

O Diabetes mellitus tipo 1 é uma doença inflamatória autoimune que acomete milhares de pessoas em todo mundo comprometendo a produtividade, qualidade de vida e sobrevida das mesmas, e que está associada a alterações nos níveis das proteínas plasmáticas ${ }^{16,17}$. Os níveis das proteínas plasmáticas também são alterados pelo tratamento com tamoxifeno, uma vez que o mesmo induz uma série de alterações hepáticas que pode levar ao comprometimento da síntese protéica, visto que a maioria das proteínas plasmáticas são sintetizadas pelo fígado, com exceção das imunoglobulinas ${ }^{6,21}$.

O modelo utilizado para estudar o efeito do diabetes e do tamoxifeno nos níveis das proteínas plasmáticas foram ratos diabéticos experimentais por estreptozotocina. A redução ou ausência de ganho de peso corporal dos animais diabéticos associada à evolução glicêmica e ao quadro visível de poliúria, polifagia e polidipsia não deixou dúvidas acerca do estado diabético dos animais utilizados, durante o período de 30 dias. Observou-se ainda, que ao longo de 30 dias os animais considerados diabéticos mantiveram o nível glicêmico superior ao dos controles. A administração do veículo em um dos grupos controles $(\mathrm{C} 1)$ foi realizada para verificar se a constituição do veículo poderia contribuir de maneira significativa no estado de hiperglicemia gerado pela condição do diabetes. Os animais do grupo $\mathrm{C} 1$ apresentaram valores de glicemia aproximados à dos animais do grupo $\mathrm{C} 2$, mostrando que a constituição do veículo utilizado para administração do TAM não alterou os níveis de glicemia dos mesmos.

Como pode ser observado na Tabela 1 e na Figura 3, os resultados obtidos para o grupo $\mathrm{C} 1$ (animais que receberam veículo) não apresentaram alterações significativas na concentração relativa e absoluta das frações protéicas quando comparados aos do C2 (animais que não receberam veículo), portanto a utilização do veículo não foi responsável pelas alterações observadas. Além disso, os valores de ambos os grupos ficaram dentro dos valores de referência geralmente indicados para cada fração do proteinograma, possibilitando a utilização do grupo controle com veículo (C1) como parâmetro de comparação para os demais grupos. 
Em relação ao grupo $\mathrm{T}$ foi possível observar alterações nas concentrações das frações albumina e a , a , b e g globulinas quando comparado ao grupo controle (Tabêla 1). Em relação à albumina, classificada como uma proteína de fase aguda negativa, houve uma redução significativa em relação ao grupo controle. Para a fração a , constituída pelas proteínas a antitripsina (principal constituinte), mucoproteínas é glicoproteína a ácida, houve um aumento não significativo quando comparado ao grupo controle. Este aumento pode ser justificado pelo fato das proteínas a antitripsina e a glicoproteína ácida serem reagentes de fase aguda positivâ podendo apresentarem-se elevadas devido a um possível processo inflamatório causado pelo TAM. Por outro lado, este aumento também poderia estar relacionado ao efeito do hiperestrogenismo sobre a a antitripsina, já que o TAM pode produzir efeitos agonistas ào do estrógeno em locais que possuem receptor de estrogênio, entre eles o fígado ${ }^{7,8}$. Já a fração a , constituída pelas proteínas haptoglobulina, a macroglôbulina e ceruloplasmina, apresentou um aumento não significativo quando comparado ao grupo controle. Deve ser observado que os valores obtidos para a fração a2 em relação ao grupo controle $(3,0 \% \pm 0,41)$ foram inferiores aos valores de referência para humanos $(5,7-11,5 \%)$, diferentemente das demais frações cujos valores foram sempre próximos aos indicados para humanos. Isto pode ser justificado, pois segundo GIANAZZA et al ${ }^{18}$, a haptoglobina está presente em ratos em concentrações inferiores a dos humanos. $\mathrm{O}$ aumento desta fração geralmente está associado a situações em que grandes quantidades de proteínas plasmáticas de baixo peso molecular, como a albumina, apresentam-se reduzidas, uma vez que para manter a pressão oncótica apenas moléculas de alto peso molecular como a a2-macroglobulina seria capaz de compensar esta função ${ }^{7}$. Em relação à fração b, onde estão presentes a transferrina, os componentes C 3 e C4 do sistema complemento, fibrinogênio, b-lipoproteína, entre outras, também pode ser observado um aumento não significativo quando comparado ao grupo controle. Este aumento poderá estar relacionado à elevação da transferrina, uma vez que segundo CHRISTENSON e SILVERMAN ${ }^{7}$ a transferrina se encontra elevada na terapia com estrogênio. Considerando que o TAM pode produzir efeito estrogênico total ou parcial, este pode provocar uma elevação da transferrina e conseqüentemente da fração b. A análise da fração $g$ mostrou um aumento não significativo quando comparado ao grupo controle. Como pode ser observado na Figura 3, o grupo T apresentou um aumento e diminuição significativa da fração a e albumina, respectivamente, caracterizando um processo de fase aguda, seguido de um leve aumento das g globulinas indicando o início de um processo de defesa.

Para o grupo D houve uma diminuição progressiva e significativa da fração albumina quando comparada ao grupo controle, podendo esta estar associada a um possível processo inflamatório, visto que a albumina é um reagente de fase aguda negativa ${ }^{16}$. Além disso, esta redução poderá está associada às glicações não-enzimáticas causadas pelo estado de hiperglicemia do Diabetes mellitus, diminuindo assim a concentração de albumina livre e aumentando a concentração de frutosamina ${ }^{7,8}$. A diminuição da albumina não poderia estar associada a uma provável microalbuminúria, geralmente causada pela nefropatia diabética, visto que o período de 30 dias seria insuficiente para desencadear uma lesão renal. Além disso, a concentração sérica de creatinina manteve-se dentro dos valores de referência durante o período de 30 dias o que também descarta a possibilidade de uma possível lesão renal (resultados não mostrados). As frações a e a permaneceram praticamente inalteradas em relação ao grupo controle, mas a análise da fração b revelou um aumento significativo quando comparado ao grupo controle e até mesmo em relação ao grupo tratado com tamoxifeno, o que poderia ser resultante do aumento do colesterol e conseqüentemente das b-lipoproteínas em função do Diabetes mellitus ${ }^{7}$. A fração g apresentou um aumento significativo quando comparado ao grupo controle e ao grupo tratado com TAM, provavelmente devido a um possível processo inflamatório associado ao $\mathrm{DM}$, visto que nesta fração se encontram as imunoglobulinas e a proteína $C$ reativa. A avaliação geral dos resultados para o grupo D, como pode ser observado na Figura 3, revela um quadro mais característico de um processo de defesa uma vez que as frações b e g apresentaram aumentos mais representativos seguido de diminuição de albumina.

Quando a condição do diabetes foi associada ao tratamento com TAM, a redução da fração albumina foi ainda mais significativa quando comparada aos demais grupos. Esta redução está relacionada a um efeito da associação entre DM e o TAM e suas respectivas alterações hepáticas. A redução da fração albumina poderia ser avaliada como um processo inicial da esteatose hepática provocada pela ação do tamoxifeno junto com o DM, ou mesmo pelo comprometimento da síntese protéica, uma vez que a biotransformação do TAM ocorre em nível hepático e seus metabólitos causam lesão do DNA dos hepatócitos ${ }^{6,21}$. Estes resultados são reforçados pelo aumento da ordem de 15 vezes da atividade das enzimas alanina aminotransferase (ALT) e aspartato aminotransferase (AST) no soro dos animais quando da associação do DM e TAM (resultados não mostrados) as quais são reconhecidas como marcadores hepáticos específicos. Estes resultados são semelhantes aos relatados na literatura, que demonstraram esteatose hepática em pacientes bem como em animais quando submetidos ao tratamento com TAM ${ }^{6,21}$. A fração a1 apresentou um aumento não significativo quando comparado ao grupo controle; este aumento poderia estar possivelmente relacionado a um processo de fase aguda e/ ou a um possível efeito específico do TAM sobre a a antitripsina, uma vez que esta proteína representa cerca dé $90 \%$ da constituição protéica da fração a . Considerando que resultados semelhantes foram obtidos apenas para o grupo tratado com TAM, mas não para o grupo $\mathrm{D}$, o aumento da a globulina no grupo DT foi causado principalmente pelo TAM. $\mathrm{O}$ aumento da fração a2 foi bastante significativo chegando a representar a somatória dos valores obtidos em condição de DM e do tratamento com TAM. Este aumento poderia ser explicado devido à progressiva diminuição da concentração 
da albumina, fazendo com que a fração a2, principalmente a a2 macroglobulina, se encontre mais elevada de modo a manter a pressão oncótica. Na região b não houve diferença significativa com relação ao grupo $\mathrm{D}$, mantendo-se um aumento significativo em relação aos demais grupos, provavelmente devido ao efeito do Diabetes mellitus sobre as lipoproteínas. Em relação à fração $g$ foi observado um aumento significativo quando comparado ao grupo controle, provavelmente devido a um processo inflamatório, visto que nesta fração se encontram as imunoglobulinas, que sofrem um aumento policlonal na maioria dos processos inflamatórios. Além disso, o aumento da proteína $\mathrm{C}$ reativa (PCR), que é a primeira proteína de fase aguda positiva a se elevar na vigência de um processo inflamatório poderá também estar contribuindo já que a ação do TAM leva à liberação de substâncias autógenas tóxicas por tecidos danificados e a PCR teria a função de remover essas substâncias tóxicas do sangue ${ }^{7,8}$.

\section{Conclusão}

A avaliação do proteinograma dos animais diabéticos tratados com tamoxifeno mostrou que a utilização do TAM por um período de 30 dias em condição de DM provocou alterações nos níveis das proteínas plasmáticas caracterizando uma resposta de fase aguda, que poderia estar relacionada a uma possível lesão hepática. Porém como o período de estudo foi curto, não foi possível observar um efeito muito agressivo, que poderá ser observado na continuidade do estudo em períodos mais prolongados. Entretanto estes resultados são representativos no que diz respeito a possível ação deletéria do TAM em nível hepático, além de confirmar os possíveis efeitos aditivos que o TAM poderia causar em pacientes diabéticos do tipo 1 .

\section{Referências}

1. Gebrim LH, Lima GR. Quimioprevenção primária e secundária do carcinoma de mama. In: Prado FC, Ramos J, Valle JR. Atualização Terapêutica 2003. 21ed. São Paulo: Artes Médicas; 2003.

2. Sharma M, Shubert DE, Sharma M, Lewis J, McGarrigle BP, Bofinger DP, Olson JR. Biotransformation of tamoxifen in a human endometrial explant culture model. Chem Biol Interact 2003; 146:237-49.

3. Bonanni B, Johansson H, Gandini S, Guerrieri-Gonzaga A, Sandri MT, Mariette F, Lien EA, Decensi A. Effect of tamoxifen at low doses on ultrasensitive C-reactive protein in healthy women. J Thromb Haemost 2003;1:2149-52.

4. Pelletier G. Localization of androgen and estrogen receptors in rat and primate tissues. Histol Histopathol 2000;15:1261-70.

5. Lewis LS, Brown K, Carthew P, Lim C, Martín EA, Styles J, White I. Chemoprevention of breast cancer by tamoxifen: risk and opportunities. Crit Rev Toxicol 2000;30:571-94.
6. Cai Q, Bensen M, Greene R, Kirchner J. Tamoxifen-induced transient multifocal hepatic fatty infiltration. Am J Gastroenterol 2000;95:277-9.

7. Christenson RH, Silverman LM. Aminoácidos e proteínas: In: Burtis CA, Ashwood ER. Fundamentos de química clínica. 4ed. Rio de Janeiro: Guanabara Koogan; 1996. p. 234-74.

8. Naoum PC. Eletroforese: técnicas e diagnósticos. 2ed. São Paulo: Santos Editora; 1999.

9. Corrêa CR, Angeleli AYO, Camargo NR, Barbosa L, Burini RC. Comparação entre a relação PCR/albumina e o índice prognóstico inflamatório nutricional (IPIN). J Bras Patol Med Lab 2002; 38: 183-90.

10. Pichet G, Bresolin PL, Pareira O, Jaworski MC, Santos CM, Pinto AP. Mucoproteína versus alfa-1-glicoproteína ácida: o que quantificar? J Bras Patol Med Lab 2002; 38: 87-91.

11. Kogika M, Pereira DA, Elias F, Notomi MK, Delayte EH, Kawahara R, Hagiwara MK. Determinação sérica de haptoglobina, ceruloplasmina e á-glicoproteína ácida em cães com gastroenterite hemorrágica. Ciência Rural 2003; 33: 513 7.

12. Bayne C, Gerwick L. The acute phase response and innate immunity of fish. Devel Comp Immunol 2001; 25: 725-43.

13. Wu X, Thomas SJ, Rendón DN, Sanford AP, Wolf SE. Insulin decreases hepatic acute phase protein levels in severely burned children. Surgery 2004; 135: 196-202.

14. Corrêa CR, Burini RC. Proteínas plasmáticas reativas de fase aguda. J Bras Patol 2000; 36: 26-34.

15. Goldsby RA, Kindt TJ, Osborne BA. Kuby - Imunologia. 4ed. Rio de Janeiro: Revinter; 2002.

16. Tan K. Dyslipidaemia, inflammation and endothelial dysfunction in diabetes mellitus. Int Congr Ser 2004; 1262: $511-4$.

17. Gomes MB, Piccirillo LJ, Nogueira VG, Matos HJ. Acutephase proteins among patients with type 1 diabetes. Diabetes Metab 2003; 29: 405-11.

18. Gianazza E, Eberini I, Villa P, Fratelli M, Pinna C, Wait R, Gemeiner M, Miller I. Monitoring effects of drug treatment in rat models of disease by serum proteins analysis. J Chomatogr B 2002; 771: 107-30.

19. Duarte VMG, Ramos AMO, Rezende LA, Macedo UBO, Neto-Brandão J, Almeida MG, Rezende AA. Osteopenia: a bone disorder associated with diabetes mellitus. J Bone Miner Metab 2005; 23: 58-68.

20. Guide for the care and use of laboratory animals, US National Conucil, 1996.

21. White IH. The tamoxifen dilemma. Carcinogenesis 1999; 20: $1153-60$. 
Silva TCP, Mota SB, Almeida MMC, Ferreira ECS, Ururahy MAG, Bezerra JF, Pereira NML, Ramos AMO, Almeida MG, Rezende AA. Effect of tamoxifen on plasma proteins in diabetes mellitus type 1. Acta Cir Bras [serial on line] Available from: URL: htt:// www.scielo.br/acb.

ABSTRACT - Purpose: Considering that important scientific advances have been obtained through studies based on experimental Diabetes mellitus, and that tamoxifen action in humans remains unknown, the aim of the present work is to follow the modifications promoted by diabetes and tamoxifen in the electrophoretic profile of plasmatic proteins. Methods: It was used 27 Wistar female rats (180-250 body weight), randomicaly divided into five groups: $\mathrm{C} 1$ ( $\mathrm{n}=3$, received vehicle), $\mathrm{C} 2$ ( $\mathrm{n}=3$, no treatment), $\mathrm{T}$ ( $\mathrm{n}=5$, treated with tamoxifen, $0.3 \mathrm{mg} / \mathrm{Kg} / \mathrm{day}), \mathrm{D}(\mathrm{n}=8$, experimental diabetes by estreptozotocin, $45 \mathrm{mg} / \mathrm{Kg}$ and $\mathrm{DT}(\mathrm{n}=8$, diabetic treated with tamoxifen). The electrophoresis was accomplished in cellulose acetate. $\mathrm{pH}$ 8.6-8.8, TECNOW chamber, and the strains were stained by Ponceau $\mathrm{S}$. The total proteins were determined by the Biuret method (Labtest). Proteinograms were obtained in densitometer BioSystems BTS-235. Results: Albumin decreased progressively in the groups T, D and DT; á1 fraction increased in groups T and DT; á2 fraction increased in groups T and D, including a synergic effect in group DT; â fraction increased in groups T and D; ã fraction increased in groups T, D and DT. Conclusions: The results indicate an acute phase resposta, with synergic effect of tamoxifen and diabetes, suggesting a probable hepatic lesion.

KEYWORDS: Tamoxifen. Plasmatic proteins. Diabetes mellitus. Electrophoresis of proteins.

Endereço para correspondência:

Adriana Augusto de Rezende

Rua Pastor Gabino Brelaz, 1401, Bloco A, apto 101, Capim Macio, CEP: 59082-010

Telefones: (84) 2079305

(84) $2154377 / 2154345$

e-mail: adrirezende@yahoo.com

Conflito de interesses: nenhum

Fonte de financiamento: nenhuma 